\title{
Caring for a person with dementia on the margins of long-term care: A perspective on burden from
}

eight European countries

Caroline Sutcliffe MSc ${ }^{\mathrm{a} *}$; Clarissa Giebel MSc${ }^{\mathrm{a}, \mathrm{i}}$; Michel Bleijlevens $\mathrm{PhD}^{\mathrm{b}}$; Connie Lethin $\mathrm{PhD}, \mathrm{RN}^{\mathrm{c}}$; Minna Stolt $\mathrm{PhD}^{\mathrm{d}}$; Kai Saks MD, $\mathrm{PhD}^{\mathrm{e}}$; Maria E. Soto MD ${ }^{\mathrm{f}}$; Gabriele Meyer PhD, RN ${ }^{\mathrm{g}}$; Adelaida Zabalegui $\mathrm{RN}, \mathrm{PhD}^{\mathrm{h}}$; Helen Chester $\mathrm{PhD}^{\mathrm{a}}$; David Challis $\mathrm{PhD}^{\mathrm{a}}$ on behalf of the RightTimePlaceCare Consortium

${ }^{\text {a }}$ Personal Social Services Research Unit: Faculty of Biology, Medicine and Health; Division of Population Health; University of Manchester: Manchester; UK

${ }^{\mathrm{b}}$ Department of Health Services Research, Care and Public Health Research Institute (CAPHRI), Maastricht University, Maastricht, The Netherlands

${ }^{c}$ Department of Health Sciences, Division of Nursing, Lund University: Lund; Sweden

${ }^{\mathrm{d}}$ Department of Nursing Science, University of Turku, and Turku University Hospital, Turku, Finland

${ }^{\mathrm{e}}$ Department of Internal Medicine, Faculty of Medicine, University of Tartu: Tartu; Estonia

${ }^{\mathrm{f}}$ Geriatrics Department, Gerontôpole, Toulouse University Hospital, INSERM UMR 1027, Toulouse, France

${ }^{\mathrm{g}}$ School of Nursing Science, Faculty of Health, University of Witten/Herdecke, Witten, and Institute for Health and Nursing Science, Medical Faculty, Martin Luther University Halle-Wittenberg: Germany

${ }^{\mathrm{h}}$ Nursing Department, Hospital Clinic of Barcelona, Spain

${ }^{\mathrm{i}}$ School of Health Sciences, University of East Anglia, Norwich, UK

*Corresponding author:

Caroline Sutcliffe

Personal Social Services Research Unit

Crawford House

University of Manchester

Manchester, UK

M13 9PL 
Tel: +44 1612755227

Email address: caroline.sutcliffe@manchester.ac.uk

\section{Running title}

A European perspective on carer burden

\section{ABSTRACT}

Objectives: To explore associations between carer burden and characteristics of 1) the informal carer, 2) the person with dementia, and 3) the care support network in eight European countries.

Design: Cross-sectional study.

Setting: People with dementia judged at risk of admission to long-term care (LTC) facilities in eight European countries (Estonia, Finland, France, Germany, Netherlands, Spain, Sweden, UK).

Participants: 1223 people with dementia supported by community services at home or receiving day care or respite care and their informal carers.

Measurements: Variables regarding the informal carer included familial relationship and living situation. Variables relating to the person with dementia included: cognitive functioning (S-MMSE); neuropsychiatric symptoms (NPI-Q); depressive symptoms (Cornell depression scale); comorbidity (Charlson Comorbidity Index); and physical functioning (Katz ADL Index). The care support network was measured using: hours of caregiving (ADLs, IADLs, supervision); additional informal care support; and service receipt (home care, day care). Experience of carer burden was recorded using the Zarit Burden Interview. Logistic regression analysis was used to determine factors associated with high carer burden.

Results: Carer burden was highest in Estonia (mean 39.7/88) and lowest in the Netherlands (mean 26.5/88). High burden was significantly associated with: characteristics of the informal carer (family relationship, specifically wives or daughters); of the person with dementia (physical dependency in ADLs; neuropsychiatric symptoms, in particular night-time behaviors and irritability); the care support network (hours of caregiving supervision; receipt of other informal care support) and country of residence.

Conclusion: A range of factors are associated with burden in informal carers of people with dementia judged to be on the margins of LTC. Support for informal carers needs to take account of gender differences. The 
dual challenges of distressed behaviours and difficulties in ADLs by the person with dementia may be addressed by specific non-pharmacological interventions focusing on both elements. The potential protective effect of additional informal support to carers highlights the importance of peer support or better targeted home support services. The implementation of appropriate and tailored interventions to reduce burden by supporting informal carers may enable people with dementia to remain at home for longer.

\section{key words for indexing:}

- dementia

- informal care

- carer burden

- older people 


\section{Introduction}

The care of people with dementia falls mainly upon the shoulders of informal carers, who also bear the largest cost.[1,2,3] As a consequence of the associated caring responsibilities, many carers can suffer psychological distress,[4,5] have poorer quality of life,[6] or experience burden.[7,8] Although the term 'burden' has negative connotations, it is acknowledged that the caring role can equally include positive aspects, $[9,10,11]$ perhaps derived from satisfaction with the potential for improving their relative's quality of life.[12] Burden has thus been described as 'the global impact of caring including both positive and negative impacts'.[13]

There is an abundance of literature, including systematic reviews, $[14,15,16]$ that have identified challenging or distressed behaviors as a significant factor in relation to increased carer burden. A review by Ornstein and Gaugler[15] showed that some behavioral symptoms such as aggression and sleep disturbance had a greater negative impact on carers. Previous research has identified gender as an influential factor in carer burden, with female carers[17,18] and wives[19,20] experiencing comparatively higher levels. Studies have also shown that higher levels of carer burden are associated with increased hours of informal caregiving.[21,14] Nevertheless, outcomes from research into carer burden have been less clear cut regarding factors such as the influence of additional informal social support to family carers,[16,22] and dependency in activities of daily living (ADLs) of people with dementia.[18,23] Furthermore, differences in outcomes between countries have been identified in previous cross-national studies.[24]

The value of research into the attributes of burden and its effects on people with dementia and carers is the potential to devise and implement more effective types of assistance or training to support informal carers in their role. A systematic review and meta-analysis has found that non-pharmacological and psychoeducational interventions have at best had only moderate impact on carer burden and distress.[25,26] The aim of this paper was to explore associations between carer burden and characteristics of 1) the informal carer, 2) the person with dementia, and 3) the care support network in eight European countries. Significantly, the study comprised a specific group of people with dementia, who were deemed to be at the margins of entry to longterm care (LTC) facilities. Existing literature has rarely focused on the experience of carer burden at a point when decisions relating to the future care of people with dementia may be considered. Thus, identifying 
factors that can be addressed in order to reduce carer burden could be beneficial for people with dementia in view of the difficulties associated with transfer to LTC.[27]

\section{Methods}

\section{Design}

This cross-sectional study was part of a large scale project (RightTimePlaceCare, RTPC) carried out in eight European countries (Estonia, Finland, France, Germany, Netherlands, Spain, Sweden and the United Kingdom (UK)). The project sought to improve health and social care services for European citizens with dementia. The objectives of this study were: to examine factors associated with transition to LTC of people with dementia around the time of admission; and investigate the health and wellbeing of people with dementia and their informal carers receiving either care in the home or in a LTC facility. A particular focus was the quality of care and quality of life of the person with dementia, and carer burden and quality of life of informal carers of people with dementia living in both care settings. Further details relating to the design and protocol of the study have been published elsewhere.[28]

\section{Sample}

Participants were recruited to the study from two care settings. The first group were people with dementia who were living at home and receiving community care services, but judged by a formal care provider (e.g. nurse, GP, social worker) responsible for their care to be at risk of admission to LTC in the next six months. Reasons for being judged at risk could vary between countries. The second group had recently made the transition to a LTC facility between one to three months previously. The present paper focused solely on the first group, being supported by community services at home, and used data collected across all eight countries. Participant inclusion criteria included: being aged 65 or above; a diagnosis of dementia; a score of 24 or less on the Standardised Mini Mental State Examination (S-MMSE) measure of cognition; being in receipt of community care services; and being supported by an informal carer who lived with or visited the person with dementia at least twice a month. Informal carers could include spouses/partners, other family members, relatives, friends, neighbours or other unpaid individuals within their social network, usually with an already existing social relationship with the cared-for person[29]. 


\section{Procedures}

Ethical approval was obtained by each country independently in accordance with their national regulations and standards. People with dementia and their carers were recruited from a variety of organisations providing home care or other community services, with a minimum of ten facilities per country to assure withincountry variation. Written informed consent was gained from all participants prior to participation in the project. Face-to-face interviews were conducted with both the person with dementia and their informal carer who also acted as the best informed proxy of their relative. These were undertaken by trained interviewers guided by a written manual and who were qualified to at least Bachelor degree level. Data were collected between November 2010 and April 2012.

\section{Measures}

Information recorded in the questionnaire included background characteristics of both the carer and person with dementia such as age, gender and marital status. Informal carers completed measures of carer burden, and hours spent caregiving. Details relating to the person with dementia included type of dementia illness, cognitive functioning, mental and physical health status, and abilities in ADLs. Care input included details of any service receipt and availability of informal support. The impact of carer burden was measured using the Zarit Burden Interview (ZBI).[30] Carers responded to 22 statements relating to the care of their relative with dementia. It used Likert scale scoring which ranged from 'Never' to 'Nearly Always'. A higher score (range 0 to 88) denoted a higher level of carer burden. The Standardised Mini Mental State Examination (SMMSE)[31,32] measured the level of cognitive impairment. Higher scores (range 0 to 30) indicated better cognitive functioning. The Charlson Comorbidity Index,[33] developed primarily to determine mortality risk, was used to record presence of chronic comorbid disease. Higher scores (range 0 to 37) indicated greater comorbidity and risk of mortality. Dependence in activities of daily living was measured using the Katz ADL index.[34] This scale rates an individual's ability to undertake six activities (dressing, bathing, eating, using the toilet, transferring, and continence). A higher score (range 0 to 6 ) denoted less physical dependency. The shortened neuropsychiatric inventory (NPI-Q) $[35,36]$ measured the presence and severity of 12 neuropsychiatric symptoms. A higher score on this measure (range 0 to 36) corresponded to a higher level of psychopathology. Presence of depressive symptoms was assessed using the Cornell Scale for Depression in Dementia (CSDD).[37] A higher score (range 0 to 38) indicated greater depressive 
symptomatology. The Resource Utilisation in Dementia instrument[38] recorded the frequency of use of community services, availability of additional informal support, and length of time devoted to informal caregiving. The latter was categorised into assistance with basic ADLs, instrumental ADLs (IADLs) (e.g. cooking, shopping) and time spent supervising the person with dementia. Supervision (or surveillance), was defined as the prevention of dangerous events, including for example risks of fire, or going outside alone or inappropriately dressed.

\section{Statistical Analysis}

Data analysis was undertaken using SPSS version 21. Scores on the ZBI were used to determine the level of carer burden. To create a binary variable using this measure, the overall median score was used to create a cut point dividing the sample into 'low' and 'high' burden groups, similar to approaches adopted or advocated elsewhere.[39,40] Chi-square tests and independent samples t-tests were used to analyze differences between the groups and identify variables significantly associated with carer burden. This exploratory analysis informed the selection of variables for the subsequent logistic regression analysis, used to explore their relationship with carer burden. Variables with large amounts of within-country missing data (type of dementia; duration of symptoms) were necessarily excluded from the regression analysis. Correlational analyses were performed to check for multicollinearity between explanatory variables. Where evidence of collinearity occurred, theoretical and statistical criteria were used to identify variables to retain in the analysis. Those retained demonstrated the strongest relationship with the dependent variable in a simple regression analysis or had the strongest theoretical reasons for their continued inclusion in the model. A multiple imputation procedure was used to impute missing data for the S-MMSE, CSDD and hours of supervision variables, analysis being undertaken using the imputed data file. To reduce the possibility of omitted variable bias in model selection,[41] backward stepwise elimination was used.

\section{Results}

\section{Sample description}

In total, 1223 people with dementia and their carers were included from the community-dwelling group receiving services. Table 1 shows the overall sample in relation to the characteristics of the carers, people with dementia, and formal and informal care input. Carers' mean age was 64.7 years (range 19 to 93 years), 
the majority were female (69\%), and were married (77\%). Most carers were either the spouse (42\%) or the daughter (32\%) of the person with dementia and 63\% of carers were co-residents. Around one third (35\%) of carers were in paid employment. The mean ZBI score of 34.2 and median of 31 indicated a moderate level of burden [40] across the eight countries. The measure showed high internal consistency $(\alpha=0.893)$. In respect of people with dementia, their mean age was 82.2 years, $63 \%$ were female and almost all (99\%) were white European. Symptom duration was on average just under five years with the majority (65\%) diagnosed with Alzheimer type dementia. The mean S-MMSE score was 14.3. Regarding care input, informal carers spent on average 2.6 hours per day assisting their relative with basic ADLs and 3.2 hours with IADLs, whilst 6.2 hours daily was spent supervising the person with dementia to prevent dangerous events. Home care was received by around half of people with dementia (49\%) and $40 \%$ attended day care. Fewer than half (45\%) of carers reported that they received support from other family or friends.

\section{[Table 1 about here]}

\section{Experience of carer burden}

Analysis of the 1216 valid ZBI scores (7 were missing or incomplete and were therefore excluded) by country showed that mean country scores ranged from the highest in Estonia (39.7, SD 16.8) to the lowest in the Netherlands (26.5, SD 12.9) (see Table 2). One-way analysis of variance showed a statistically significant difference between countries $(\mathrm{F}(7,1208)=12.64, \mathrm{p}<.001)$. A Games-Howell post-hoc test revealed that the mean ZBI score in Estonia was statistically significantly higher than in all other countries except Spain and UK. Furthermore, the mean ZBI score in the Netherlands was significantly lower than all countries except Finland (see Table 3).

\section{[Table 2 and Table 3 about here]}

Differences in level of carer burden in relation to characteristics of the carer, person with dementia, and care input are shown in Table 4 using bivariate analyses. There were no significant differences between respondents in respect of carer age and their marital or employment status. Female carers, (wives and daughters) and co-resident carers reported higher levels of burden. Those in the high burden group were more likely to be carers of males with dementia. Experience of burden was also associated with younger age of the person with dementia, longer duration of dementia symptoms and higher scores on each of the standardized measures: cognitive functioning; ADL dependency; neuropsychiatric and depressive symptoms; and comorbidity. More hours of informal care input in relation to ADLs, IADLs, and supervision were 
associated with higher levels of burden. Whilst there was no significant association between carer burden and use of day care, carers of relatives in receipt of home care and carers receiving informal support from other sources were significantly less likely to experience high levels of burden.

\section{[Table 4 about here]}

Logistic regression analyses were undertaken using those variables identified in Tables 2 and 4 which showed statistically significant associations with carer burden using bivariate analyses. Variables with many non-random missing values were excluded (duration of symptoms; type of dementia). Table 5 shows that six factors were significantly associated with level of carer burden. With regard to informal carer characteristics, wives and daughters were significantly more likely to experience higher levels of carer burden than any other caring relative. Although a $\chi^{2}$ test identified an association between carer gender and burden, this variable was not retained within the final regression analysis, as this was only significant at the $10 \%$ level $(\mathrm{p}=0.081)$. In respect of the person with dementia, both physical dependency in ADLs, and greater neuropsychiatric symptomatology were associated with higher burden. Subsequent analysis of the data showed that the symptoms that carers reported as most severe and distressing were night-time behaviours $[\mathrm{beta}=0.202$, (SE.04) $\mathrm{OR}=1.22, \mathrm{p}<0.001]$ and irritability [beta=0.208, (SE.05) $\mathrm{OR}=1.23, \mathrm{p}<0.001]$. Carers who received other informal care support were significantly less likely to report high burden as were those who spent fewer hours supervising their relative. Country was also a significant factor, with carers in Estonia more likely to experience high burden and carers in the Netherlands much less so. France was selected as the reference category to represent the country whose mean ZBI score most closely matched the overall mean value (see Table 2).

\section{[Table 5 about here]}

\section{Discussion}

This large scale cross-national study has considered the experience of burden of informal carers of people with dementia living in the community and receiving care services. Differences were found between countries in experience of carer burden. A number of significant determinants were identified in respect of the carer's relationship to the person with dementia, specifically wives and daughters; the person with dementia's neuropsychiatric symptoms in particular night-time behaviors and irritability, and their dependency in ADLs; care input in hours of supervision and additional informal care support; and country of 
residence. The strengths of this study lie in the large cohort size which combined data from several European countries and incorporated a large range of measures including service receipt. One of its most notable features was the focus upon people with dementia on the cusp of admission to LTC. Since the link between burden of dementia caring and subsequent carer breakdown and transition to LTC is well established,[42,43] the findings may be particularly salient for the development of appropriate interventions directed towards family carers and are explored in more detail below.

Carer characteristics such as gender and burden did not appear to be associated in this study. However, the relationship between carer and the person with dementia, which accounted for both gender and family affiliation, was significant. Carers who were daughters or wives were significantly more likely to report feelings of burden than husbands, sons, or others, consistent with research elsewhere.[19,39] It has been found that wives experience more 'role burden' in relation to the demands of the caring role, whilst daughters report higher 'personal burden' related to feelings of adequacy in caregiving.[44] In contrast, other research has shown higher levels of burden in adult child carers especially if they lived with the person with dementia.[45] Although co-residence was significantly associated with burden using binary analysis in this study, this variable was not retained in the final regression analysis. Nevertheless, the finding that wives and daughters experienced greater burden is noteworthy since the majority of informal (and formal) care is undertaken by women. As a consequence these gender differences need to be reflected in the design and implementation of appropriate and tailored interventions.[46]

With respect to the characteristics of the person with dementia, there was a significant relationship between neuropsychiatric symptoms and carer burden, consistent with other research.[14,24] Disturbed night-time behavior may interfere with the sleep quality of a co-resident carer and consequently their ability to undertake daytime caring tasks. The negative effect of sleep disturbance has been identified elsewhere[15] as has the association between night-time wandering and carer burden.[23] Despite evidence of the negative impact of challenging behaviours on carer burden, non-pharmacological interventions that focus purely on behavior management have been less effective than those which incorporate stress-coping mechanisms for carers.[47,48] Brodaty and Arasaratnam[49] found that interventions to reduce distressed behaviors exhibited by the person with dementia and the carers' negative reactions to these, may be successful if they are 
multicomponent, individually tailored to the recipients and provided in the home environment. Functional dependency was associated with carer burden, although other research appears equivocal on this.[18,21] Caring for someone with both challenging behaviors and requiring assistance with ADLs has been described as a 'dual challenge'.[50] The latter research found that ADL impairment, female carer gender and 'resistiveness to care' by the person with dementia during help with ADLs were associated with poor carer well-being, requiring specific carer interventions that focus on the distressed behaviors of the person with dementia arising during assistance with personal care tasks.

Outcomes relating to care input indicated an association between higher levels of supervision and increased carer burden, also identified within a similar European study.[51] Provision of informal support to the carer appeared to act as a protective factor, consistent with the wider social network literature[52], and those receiving additional home care support perceived less burden, which is in contrast to other research.[22] In this study there were no gender differences between male and female carers in the proportion who received additional informal support ( $43 \%$ versus $45 \%$ respectively). Social support may act as a mediating factor, and has been identified as an important element in the resilience of carers of people with dementia.[53] Some systematic reviews and meta-analyses have found that support groups for carers can impact positively upon carers' psychological well-being and experience of burden.[54,55] Furthermore, Han and colleagues [56] identified the effect of different types of support, for example psychological burden could be ameliorated by affectionate and social support whilst tangible hands-on support moderated non-psychological burden. Research investigating carer preferences for home support services found that carers' most preferred attribute was support with personal feelings and concerns, from a trained counsellor at home.[57] This suggests that home care provision which contains elements of carer support may be valued. It is notable that receipt of home care was not significantly related to carer burden. A lack of association between formal service use and burden has been reported elsewhere[17,58]. This study measured service receipt later in the trajectory of care. Service provision at this point may have been unable to influence perceived burden. At earlier stages of dementia, formal care may substitute for informal care whilst at later stages they supplement but cannot replace family care, highlighting the need for more tailored or intensive support. 
The present study established that levels of burden varied by country, a similar outcome to other crossnational studies of carer burden.[13,24] Carer burden in Estonia was significantly higher than in all countries except the UK, and in the Netherlands significantly lower than in all countries except Finland. There are a number of possible explanations for this outcome. An examination of data from the RTPC project[6,59] indicated that Estonia had the youngest carers, one of the highest proportions of adult child carers, and the highest rate of carers in paid employment. This suggests the possibility that carers in Estonia had additional caring obligations such as child care and/or other work commitments outside the home. Furthermore, carers in Estonia reported significantly more hours assisting with ADLs (173/month) and those in the Netherlands significantly fewer hours (29/month) compared to the overall average (79/month). Estonia reported the second highest hours providing IADL assistance per month (156/month) in contrast to the Netherlands with the lowest (29/month) compared to the overall average (96/month). The number of hours per day carers in Estonia spent supervising their relative was significantly higher than in most other countries. Furthermore, levels of health and social care support, socio-economic factors, or cultural obligations may vary between countries explaining national differences.[60] Nevertheless there are limitations to this study. First, the study design being cross-sectional in nature means that it is not possible to infer causal relationships between care burden and the outcome variables. Second, higher levels of within-country missing data relating to the person with dementia led to the exclusion of potentially pertinent variables from the analyses. Third, the particular focus on people with dementia deemed at risk of admission to LTC would indicate that the results may not be generalizable to a wider population of people with dementia, only to this high risk group. However, this focus means that findings may be of particular relevance to service commissioners, planners, and providers in delivering tailored and appropriate interventions to support informal carers and to prevent or delay costly admission to hospital or LTC.

\section{Conclusion}

This paper has reported findings from a large pan-European study focusing on people with dementia on the margins of LTC and consequently at a crucial point in their lives. A number of factors were associated with burden related to characteristics of the informal carer, the person with dementia, care input and country of residence. The higher levels of burden in wives and daughters suggest that support for informal carers should consider gender differences. The dual challenges of distressed behaviours and difficulties performing ADLs 
by the person with dementia may be addressed by specific non-pharmacological interventions which simultaneously focus on both elements. Receiving extra informal support may have a potential protective effect against carer burden and thus emotional or peer support and better targeted home support may be beneficial. Carer burden is acknowledged as an important factor in subsequent admission to LTC[44]. Therefore reducing burden for this particular group by the implementation of appropriate and tailored interventions could have positive impacts on informal carer health and may also have wider cost benefits[3,61] and enable people with dementia to remain at home for longer.

\section{Acknowledgements}

The authors would like to thank Hanneke Beerens for her advice and help with data preparation.

\section{Funding}

This work was supported by a grant from the European Commission within the 7th Framework Programme (project 242153). The funder had no involvement in the design or execution of the study, or the writing of this article.

\section{Conflicts of interest}

None 
Table 1 Sample characteristics

$\mathrm{N}=961 \min \mathrm{N}=1223 \max ^{*}$

Carer

Mean age in years (SD)

$64.7(13.4)$

Female (\%)

839 (68.6)

Relationship to person with dementia (\%)

Husband

Wife

$273(22.4)$

Daughter

$391(32.0)$

Son

161(13.2)

Other

$159(13.0)$

Married (\%)

946 (77.4)

Employed (\%)

430 (35.2)

Lives with person with dementia $(\%)$

767 (62.8)

ZBI score (SD)

\section{Person with dementia}

Mean age in years (SD)

Female (\%)

$775(63.4)$

Ethnicity (\%)

White/European

1032 (98.6)

Hispanic

Black/Asian

Duration of symptoms in year (SD)

$4.9(3.7)$

Type of dementia (\%)

Alzheimer's
Vascular
Mixed
Other (Lewy Body, Fronto-temporal etc)

$664(65.0)$

200 (19.6)

$72(7.1)$

85 (8.3)

S-MMSE score (SD)

$14.3(6.6)$

Katz ADL score (SD)

NPI-Q score - severity (SD)

$9.4(6.4)$

Cornell depression score (SD)

$8.2(6.0)$

Charlson comorbidity score (SD)

$2.1(1.4)$

\section{Care input}

Hours/ day ADL caregiving (SD)

Hours/ day IADL caregiving (SD)

Hours/ day supervising PwD (SD)

Person with dementia receives home care $(\%)$

Person with dementia receives day care $(\%)$ 496 (40.6) 


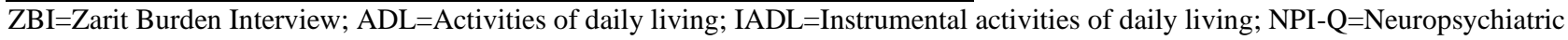
Inventory Questionnaire; S-MMSE=Standardised Mini-Mental State Examination

* Indicates minimum and maximum $\mathrm{N}$ values for variables 
Table 2 Zarit Burden Interview score by country

\begin{tabular}{lcl}
\hline Country & $\mathrm{N}$ & Mean (SD) \\
\hline Estonia & 169 & $39.7(16.8)$ \\
UK & 81 & $36.7(18.5)$ \\
Spain & 174 & $35.1(15.3)$ \\
France & 173 & $32.1(16.2)$ \\
Germany & 116 & $31.7(13.2)$ \\
Sweden & 146 & $31.6(16.2)$ \\
Finland & 180 & $28.5(14.1)$ \\
Netherlands & 177 & $26.5(12.9)$ \\
Total & 1216 & $32.4(15.8)$ \\
\hline
\end{tabular}


Table 3 Zarit Burden Interview score - differences by country

\begin{tabular}{l|r|r|r|r}
\hline \multicolumn{5}{c}{ Mean difference in scores* } \\
\hline & P value & Estonia & P value & Netherlands \\
\hline UK & N.S. & 2.92 & $\mathrm{p} \leq 0.001$ & -10.21 \\
Spain & $\mathrm{p} \leq 0.001$ & 4.55 & $\mathrm{p} \leq 0.001$ & -8.58 \\
France & $\mathrm{p} \leq 0.001$ & 7.55 & $\mathrm{p} \leq 0.01$ & -5.58 \\
Germany & $\mathrm{p} \leq 0.001$ & 7.98 & $\mathrm{p} \leq 0.05$ & -5.14 \\
Sweden & $\mathrm{p} \leq 0.001$ & 8.07 & $\mathrm{p} \leq 0.05$ & -5.05 \\
Finland & $\mathrm{p} \leq 0.001$ & 11.20 & $\mathrm{~N} . \mathrm{S}$ & -1.93 \\
Netherlands & $\mathrm{p} \leq 0.001$ & 13.12 & & - \\
Estonia & & & & $\mathrm{p} \leq 0.001$ \\
\end{tabular}

*Games-Howell post-hoc test 
Table 4 Comparison of sample characteristics split by low/high carer burden

\begin{tabular}{|c|c|c|c|}
\hline & $\begin{array}{l}\text { Low } \\
\text { burden } \\
\mathrm{N}=622\end{array}$ & $\begin{array}{l}\text { High burden } \\
\mathrm{N}=594\end{array}$ & Sig. \\
\hline \multicolumn{4}{|l|}{ Carer } \\
\hline Age (years) & 64.9 & 63.5 & $\mathrm{p}=0.061$ \\
\hline Gender & & & $\chi^{2}=31.82,(1 \mathrm{df}) \mathrm{p}<0.001$ \\
\hline Male & $239(38 \%)$ & $139(62 \%)$ & \\
\hline Female & $382(23 \%)$ & $453(77 \%)$ & \\
\hline Relationship to person with dementia & & & $\chi^{2}=31.9,(4 \mathrm{df}) \mathrm{p}<0.001$ \\
\hline Husband & $120(51 \%)$ & $115(49 \%)$ & \\
\hline Wife & $127(47 \%)$ & $145(53 \%)$ & \\
\hline Daughter & $171(44 \%)$ & $219(56 \%)$ & \\
\hline Son & $105(66 \%)$ & $55(34 \%)$ & \\
\hline Other & $98(62 \%)$ & $59(38 \%)$ & \\
\hline Married & $465(77 \%)$ & $478(78 \%)$ & $\mathrm{p}=0.582$ \\
\hline Employed & $208(35 \%)$ & $219(35 \%)$ & $\mathrm{p}=1.00$ \\
\hline Lives with person with dementia & $342(55 \%)$ & $419(71 \%)$ & $\chi^{2}=31.87,(1 \mathrm{df}) \mathrm{p}<0.001$ \\
\hline \multicolumn{4}{|l|}{ Person with dementia } \\
\hline Age & 82.6 & 81.8 & $\mathrm{t}=2.4(1190 \mathrm{df}) \mathrm{p}=0.018$ \\
\hline Gender & & & $\chi^{2}=15.10,(1 \mathrm{df}) \mathrm{p}<0.001$ \\
\hline Male & $195(44 \%)$ & $250(56 \%)$ & \\
\hline Female & $427(55 \%)$ & $344(45 \%)$ & \\
\hline Duration of symptoms (years) & 4.6 & 5.2 & $\mathrm{t}=2.61(948 \mathrm{df}) \mathrm{p}=0.009$ \\
\hline Type of dementia & & & $\chi^{2}=12.11(3 \mathrm{df}) \mathrm{p}=0.007$ \\
\hline Alzheimer's & $363(55 \%)$ & $298(45 \%)$ & \\
\hline Vascular & $91(46 \%)$ & $107(54 \%)$ & \\
\hline Mixed & $36(50 \%)$ & $36(50 \%)$ & \\
\hline Other (Lewy Body, Fronto-temporal etc) & $32(38 \%)$ & $53(62 \%)$ & \\
\hline S-MMSE & 15.1 & 13.4 & $\mathrm{t}=-4.31(1020 \mathrm{df}) \mathrm{p}<0.001$ \\
\hline Katz ADL score & 3.6 & 3.0 & $\mathrm{t}=-5.25(1201 \mathrm{df}) \mathrm{p}<0.001$ \\
\hline Neuropsychiatric symptoms - severity & 7.3 & 11.6 & $\mathrm{t}=-12.3(1145 \mathrm{df}) \mathrm{p}<0.001$ \\
\hline Cornell depression score & 6.2 & 10.3 & $\mathrm{t}=11.93(979 \mathrm{df}) \mathrm{p}<0.001$ \\
\hline Charlson comorbidity & 2.00 & 2.23 & $\mathrm{t}=-2.92(1181 \mathrm{df}) \mathrm{p}=0.004$ \\
\hline \multicolumn{4}{|l|}{ Care input } \\
\hline 3 hours + per day ADL caregiving & $114(19 \%)$ & $230(39 \%)$ & $\chi^{2}=61.45(1 \mathrm{df}) \mathrm{p}<0.001$ \\
\hline 3 hours + per day IADL caregiving & $242(40 \%)$ & $333(56 \%)$ & $\chi^{2}=34.67(1 \mathrm{df}) \mathrm{p}<0.001$ \\
\hline 8 hours + per day supervising PwD & $123(21 \%)$ & $223(39 \%)$ & $\chi^{2}=45.70(1 \mathrm{df}) \mathrm{p}<0.001$ \\
\hline Receives home care & $321(52 \%)$ & $236(40 \%)$ & $\chi^{2}=17.27(1 \mathrm{df}) \mathrm{p}<0.001$ \\
\hline Receives day care & $227(37 \%)$ & $232(39 \%)$ & $\mathrm{p}=0.375$ \\
\hline Use of dementia specific services & $276(45 \%)$ & $279(47 \%)$ & $\mathrm{p}=0.405$ \\
\hline
\end{tabular}


Carer receives informal support

$302(49 \%) \quad 232(40 \%) \quad \chi^{2}=10.50(1 \mathrm{df}) \mathrm{p}=0.001$

S-MMSE=Standardised Mini-Mental State Examination; ADL=Activities of daily living; IADL=Instrumental activities of daily living; PwD=Person with dementia 
Table 5 Logistic regression analysis of factors associated with carer burden

\begin{tabular}{|c|c|c|c|c|c|}
\hline \multirow[t]{2}{*}{ Variables in the final model } & \multirow[t]{2}{*}{$\mathbf{B}$} & \multirow[t]{2}{*}{ SE } & \multirow[t]{2}{*}{ Sig } & & $95 \% \mathrm{CI}$ \\
\hline & & & & \multicolumn{2}{|l|}{ Ratio } \\
\hline Constant & -1.091 & 0.324 & .001 & 0.34 & $0.18-0.63$ \\
\hline \multicolumn{6}{|l|}{ Relationship to the person with dementia: } \\
\hline \multicolumn{6}{|l|}{ Husband (reference group) } \\
\hline Wife & 0.543 & .210 & .010 & 1.72 & $1.14-2.60$ \\
\hline Daughter & 0.510 & 0.213 & .017 & 1.67 & $1.10-2.53$ \\
\hline Son & -0.442 & 0.266 & .097 & 0.64 & $0.38-1.08$ \\
\hline Other relative/friend & -0.433 & 0.264 & .101 & 0.65 & $0.39-1.09$ \\
\hline KATZ ADL score & -0.078 & 0.036 & .033 & 0.93 & $0.86-0.99$ \\
\hline Neuropsychiatric symptoms (NPI-Q) & 0.123 & 0.012 & $<.001$ & 1.13 & $1.11-1.16$ \\
\hline Hours per day supervising PwD & -0.570 & 0.166 & .001 & 0.57 & $0.41-0.78$ \\
\hline Carer receives other informal support & 0.513 & 0.141 & $<.001$ & 1.67 & $1.27-2.20$ \\
\hline \multicolumn{6}{|l|}{ Country: } \\
\hline \multicolumn{6}{|l|}{ France (reference group) } \\
\hline Sweden & 0.031 & 0.272 & .909 & 1.03 & $0.61-1.76$ \\
\hline Finland & -0.180 & 0.254 & .480 & 0.84 & $0.51-1.38$ \\
\hline Germany & 0.070 & 0.285 & .805 & 1.07 & $0.61-1.87$ \\
\hline Estonia & 0.907 & 0.272 & .001 & 2.48 & $1.45-4.22$ \\
\hline Spain & 0.461 & 0.253 & .069 & 1.59 & $0.97-2.60$ \\
\hline UK & 0.177 & 0.314 & .574 & 1.19 & $0.64-2.21$ \\
\hline Netherlands & -0.834 & 0.267 & .002 & 0.43 & $0.26-0.73$ \\
\hline \multicolumn{6}{|l|}{$\mathrm{n}=1170$} \\
\hline \multicolumn{6}{|l|}{ Pooled Pseudo $\mathrm{R}^{2}=28.8 \%$} \\
\hline Hosmer-Lemeshow $\chi^{2}=.488$ & & & & & \\
\hline
\end{tabular}




\section{References}

1. Wimo A, Jönsson L, Bond J, et al. The worldwide economic impact of dementia 2010. Alzheimers Dement 2013a; 9:1-11.

2. Wimo A, Reed C, Dodel R, Belger, et al. The GERAS Study: A prospective observational study of costs and resource use in community dwellers with Alzheimer's Disease in three European Countries - Study Design and baseline findings. J Alzheimers Dis 2013; 36:385-399.

3. Farre M, Haro, JM, Kostov B, Alvira C, et al. Direct and indirect cost and resource in dementia care: A Cross-sectional study in patients at home. Int J Nurs Stud 2016; 55:39-49.

4. Lethin C, Renom-Guiteras A, Zwakhalen S, et al. Psychological well-being over time among informal caregivers caring for persons with dementia living at home. Aging Ment Health 2016: http://dx.doi.org/10.1080/13607863.2016.1211621.

5. Honyashiki M, Ferri CL, Acosta D, et al. Chronic diseases among older people and co-resident psychological morbidity: a 10/66 Dementia Research Group population-based survey. Int Psychogeriatr 2011; 23:1489-1501.

6. Bleijlevens MHC, Stolt M, et al. Changes in caregiver burden and health-related quality of life of informal caregivers of older people with Dementia: evidence from the European RightTimePlaceCare prospective cohort study. J Adv Nurs 2015; 71:1378-1391.

7. Burns A, Rabins P. Carer burden in dementia. Int J Geriatr Psych 2000;15:S9-S13.

8. Jones R.W, Romeo R, Trigg R et al. Dependence in Alzheimer's disease and service use costs, quality of life, and caregiver burden: The DADE study. Alzheimers Dement 2015; 11: 280-290.

9. Tarlow B.J, Wisniewski S.R, Belle S, et al. Positive aspects of caregiving. Res Aging 2004; 26:429-453.

10. Peacock S, Forbes D, Markle-Reid M, et al. The positive aspects of the caregiving journey with dementia: Using a strengths-based perspective to reveal opportunities. J Appl Gerontol 2010; 29:640-659.

11. Alvira C, Risco E, Cabrera E, Farré M, et al. The association between positive-negative reactions of informal caregivers of people with dementia and health outcomes in eight European countries: a crosssectional study. J Adv Nurs 2015; 71:1417-1434. 
12. McDaid D. Estimating the costs of informal care for people with Alzheimer's disease: methodological and practical challenges. Int J Geriatr Psych 2001;16: 400-405.

13. Schneider J, Murray J, Banerjee S, Mann A. EUROCARE: A cross-national study of co-resident spouse carers for people with Alzheimer's disease: I - factors associated with carer burden. Int J Geriatr Psych 1999; 14: 651-661.

14. Pinquart M, Sorensen S. Association of stressors and uplifts of caregiving with caregiver burden and depressive mood: A meta-analysis. J Gerontol B Psychol 2003; 58: 112-128.

15. Ornstein K, Gaugler JE. The problem with "problem behaviors": a systematic review of the association between individual patient behavioural and psychological symptoms and caregiver depression and burden within the dementia patient-caregiver dyad. Int Psychogeriatr 2012; 24: 1536-1552.

16. van der Lee J, Bakker TJEM, Duivenvoorden HJ et al. Multivariate models of subjective caregiver burden in dementia: A systematic review. Ageing Res Rev 2014; 15: 76-93.

17. Gallicchio L, Siddiqi N, Langenberg $\mathrm{P}$ et al. Gender differences in burden and depression among informal caregivers of demented elders in the community. Int J Geriatr Psych 2002; 17: 154-163.

18. Campbell P, Wright J, Job D, et al. Determinants of burden in those who care for someone with dementia. Int J Geriatr Psych 2008; 23: 1078-1085.

19. Barusch AS, Spaid WM. Gender differences in caregiving: Why do wives report greater burden? Gerontologist 1989; 29: 667-676.

20. Thompson RT, Lewis SL, Murphy MR. Are there sex differences in emotional and biological responses in spousal caregivers of patients with Alzheimer's disease? Biol Res Nurs 2004; 5: 319-330.

21. Conde-Sala JL, Turró-Garriga O, Calvó-Perxas L, et al. Three-year trajectories of caregiver burden in Alzheimer's disease. J Alzheimers Dis 2014; 42: 623-633.

22. Chappell NL, Reid RC. Burden and well-being among caregivers: Examining the distinction. Gerontologist 2002; 42: 772-780.

23. Wolfs C, Kessels A, Severens J, et al. Predictive factors for the objective burden of informal care in people with dementia. Alzheimer Dis Assoc Disord 2012; 26:197-204. 
24. Bergvall N, Brinck P, Eek D. et al. Relative importance of patient disease indicators on informal care and caregiver burden in Alzheimer's disease. Int Psychogeriatr 2011; 23: 73-85.

25. Brodaty H, Green A, Koschera A. Meta-analysis of psychosocial interventions for caregivers of people with dementia. JAGS 2003; 51:657-664.

26. Jensen M, Agbata IN, Canavan M, McCarthy G. Effectiveness of educational interventions for informal caregivers of individuals with dementia residing in the community: systematic review and meta-analysis of randomised controlled trials. Int J Geriatr Psych 2015; 30: 130-143.

27. Sury L, Burns K, Brodaty H. Moving in: adjustment of people living with dementia going into a nursing home and their families. Int Psychogeriatr 2013; 25:867-876.

28. Verbeek H, Meyer G, Leino-Kilpi H, et al. A European study investigating patterns of transition from home care towards institutional dementia care: the protocol of a RightTimePlaceCare study. BMC Public Health 2012; 12:68.

29. The Organisation for Economic Co-operation \& Development. The OECD Health Project. Long-term Care for Older People. Paris: OECD Publishing, 2005.

30. Zarit SH, Reever KE, Bach-Peterson J. Relatives of the impaired elderly: correlates of feelings of burden. Gerontologist 1980; 20: 649-655.

31. Folstein M, Folstein S, McHugh P. "Mini-mental state". A practical method for grading the cognitive state of patients for the clinician. J Psychiat Res 1975; 12: 189-198.

32. Molloy DW, Alemayehu E, Roberts R. Reliability of a standardized mini-mental state examination compared with the traditional mini-mental state examination. Am J Psychiat 1991; 148: 102-105.

33. Charlson ME, Pompei P, Ales KL, MacKenzie CR. A new method of classifying prognostic comorbidity in longitudinal studies: Development and validation. J Chronic Dis 1987; 40:373-383.

34. Katz S. Assessing self-maintenance: Activities of daily living, mobility and instrumental activities of daily living. J Am Geriatr Soc 1983; 31: 721-726.

35. Cummings JL, Mega M, Gray K et al. The Neuropsychiatric Inventory: comprehensive assessment of psychopathology in dementia. Neurology 1994; 44:2308-2314. 
36. Kaufer DI, Cummings JL, Ketchel P, et al. Validation of the NPI-Q, a Brief Clinical Form of the Neuropsychiatric Inventory. J Neuropsych Clin N 2000;12: 233-239.

37. Alexopoulos GS, Abrams RC, Young RC, Shamoian CA. Cornell Scale for depression in dementia. Biol Psychiatry 1988; 23:271-284.

38. Wimo A, Mastey V, Winblad B. Evaluation of the resource utilization and caregiver time in antidementia drug trials - a quantitative battery. In: Wimo A, Karlsson G, Winblad B, eds. The Health Economics of Dementia. London: John Wiley and Sons, 1998.

39. Coen RF, Swanwick GR, O'Boyle C, et al. Behaviour disturbance and other predictors of carer burden in Alzheimer's disease. Int J Geriatr Psych 1997;12: 331-336.

40. Hérbert R, Bravo G Préville M. Reliability, validity and reference values of the Zarit Burden Interview for assessing informal caregivers of community-dwelling older persons with dementia. Can J Aging 2000; 19:494-507.

41. Field A. Discovering statistics using SPSS. $3^{\text {rd }}$ ed. London: SAGE publications, 2009.

42. Torti F, Gwyther L, Reed S, et al. A Multinational Review of Recent Trends and Reports in Dementia Caregiver Burden. Alzheimer Dis Assoc Disord 2004; 18:99-109.

43. Yaffe K, Fox P, Newcomer R, et al. Patient and Caregiver Characteristics and Nursing Home Placement in Patients With Dementia. JAMA 2002; 287: 2090-2097.

44. Bedard M, Kuzik R, Chambers L. Understanding burden differences between men and women caregivers: the contribution of care-recipient problem behaviors. Int Psychogeriatr 2005; 17:99-118.

45. Conde-Sala JL, Garre-Olmo J, Turró-Garriga O, et al. Differential features of burden between spouse and adult-child caregivers of patients with Alzheimer's disease; An exploratory comparative design. Int J Nurs Stud 2010; 47:1262-1273.

46. Errol R, Brooker D, Peel E. Women and Dementia: A Global Research Review. London: Alzheimer Disease International (ADI), 2015.

47. Burns R, Nichols LO, Martindale-Adams J, et al. Primary care interventions for dementia caregivers: 2year outcomes from the REACH study. Gerontologist 2003; 43:547-555. 
48. Graff MJL, Vernooij-Dassen JM, Thijssen M, et al. Community based occupational therapy for patients with dementia and the care givers: randomised controlled trial. BMJ 2006; doi:10.1136/bmj.39001.688843.BE

49. Brodaty H, Arasaratnam C. Meta-analysis of nonpharmacological interventions for neuropsychiatric symptoms of dementia. Am J Psychiat 2012; 169:946-953.

50. Fauth EB, Femia EE, Zarit SH. Resistiveness to care during assistance with activities of daily living in non-institutionalized persons with dementia: associations with informal caregivers' stress and well-being Aging Ment Health 2016; 20:888-898.

51. Haro JM, Kahle-Wrobleski K, Bruno G, et al. Analysis of burden in caregivers of people with Alzheimer's disease using self-report and supervision hours. J Nutr Health Aging 2014; 18: 677-684.

52. Weiss R. The provisions of social relationships. In: Rubin Z, ed. Doing unto others. Englewood Cliffs, New Jersey: Prentice Hall, 1974.

53. Joling KJ, Windle G, Dröes R, et al. What are the essential features of resilience for informal caregivers of people living with dementia? A Delphi consensus examination. Aging Ment Health 2015. Available at http://dx.doi.org/10.1080/13607863.2015.1124836. Accessed 27 May 2016.

54. Chien L, Chu H, Guo JL et al. Caregiver support groups in patients with dementia: a meta-analysis. Int J Geriatr Psych 2011; 26:1089-1098.

55. Adelman RD, Tmanova LL, Delgado D, et al. Caregiver burden: A clinical review. JAMA 2014; 311:10.

56. Han JW, Jeong H, Park JY, et al. Effects of social supports on burden in caregivers of people with dementia Int Psychogeriatr 2014; 26:1639-1648.

57. Chester H, Clarkson P, Davies L, et al. Patient and carer preferences for home support services in early stage dementia. Aging Ment Health 2016; doi: 10.1080/13607863.2016.1247424.

58. Robinson KM, Buckwalter K, Reed D. Differences between dementia caregivers who are users and nonusers of community services. Public Health Nurs 2005; 30:501-510.

59. Bremer P, Cabrera E, Leino-Kilpi H, et al. Informal Dementia Care: Consequences for Caregivers' Health and Health Care Use in 8 European Countries. Health Policy 2015; 119:1459-71. 
60. Germain S, Adam S, Olivier C, et al. Does cognitive impairment influence burden in caregivers of patients with Alzheimer's Disease? J Alzheimers Dis 2009; 17:105-114.

61. Vossius C, Rongve A, Testad I, et al. The use and costs of formal care in newly diagnosed dementia: A three-year prospective follow-up study. Am J Geriat Psychiat 2014;22: 381-388. 


\section{Appendix 1}

The RightTimePlaceCare Consortium partners are as follows:

\section{Coordinator:}

University of Witten/Herdecke (DE): Gabriele Meyer, PhD, RN, scientific coordinator of the RightTimePlaceCare project; Astrid Stephan, MSc, RN; Anna Renom-Guiteras; Dirk Sauerland, PhD; Ansgar Wübker, PhD; Patrick Bremer.

\section{Consortium Members:}

Maastricht University (NL): Jan P.H. Hamers, PhD, RN; Basema Afram, MSc; Hanneke C. Beerens, MSc, RN; Michel H.C. Bleijlevens, PhD, PT; Hilde Verbeek, PhD; Sandra M.G. Zwakhalen, PhD, RN;

Dirk Ruwaard, PhD, MD; Ton Ambergen, $\mathrm{PhD}$.

Lund University (SE): Ingalill Rahm Hallberg, PhD; Ulla Melin Emilsson, PhD; Staffan Karlsson, PhD; Christina Bökberg, MSc, RN; Connie Lethin, PhD, RN.

University of Manchester (England): David Challis, PhD; Caroline Sutcliffe, MSc; David Jolley, PhD; Sue Tucker, MSc, RN; Ian Bowns, PhD; Brenda Roe, PhD; Alistair Burns, PhD.

University of Turku (FI): Helena Leino-Kilpi, PhD, RN; Jaana Koskenniemi, MSc, RN; Riitta Suhonen, PhD, RN; Matti Viitanen, PhD, MD; Seija Arve, PhD, RN; Minna Stolt, PhD; Maija Hupli, PhD, RN.

University of Tartu (EE): Kai Saks, PhD, MD; Ene-Margit Tiit, PhD; Jelena Leibur, MD; Katrin Raamat, MA; Angelika Armolik, MA; Teija Tuula Marjatta Toivari, MA, RN.

Fundació Privada Clinic per la Recerca Biomedica, Hospital Clinic of Barcelona (ES): Adelaida Zabalegui, PhD, RN; Montserrat Navarro, PhD, RN; Esther Cabrera, PhD, RN (Tecnocampus Mataró); Ester Risco, MSc, RN; Carme Alvira, MSc, RN; Marta Farre, MSc, RN; Susana Miguel, MSc, RN.

Gerontôpole, University of Toulouse (FR): Maria Soto, MD; Agathe Milhet; Sandrine Sourdet, MD; Sophie Gillette; Bruno Vellas, PhD. 